\title{
Radionuclides Contamination in Soil: Effects, Sources and Spatial Distribution
}

\author{
Peter Oluwadamilare Olagbaju ${ }^{1}$, Olanrewaju Bola Wojuola ${ }^{1}$, and Victor Tshivhase ${ }^{2}$ \\ ${ }^{1}$ Department of Physics, North-West University, Mafikeng Campus, Mmabatho, South Africa \\ ${ }^{2}$ Centre for Applied Radiation Science and Technology, North-West University, Mafikeng Campus, \\ Mmabatho, South Africa \\ corresponding author: olagbajupetero@gmail.com
}

\begin{abstract}
Radionuclide concentrations in the soil depend on the geological and anthropogenic activities of an area. They influence level of gamma radiation in the environment, which can cause significant health risk in humans. Due to the non-uniform distribution of radionuclides in the soil, various measurement methods have been adopted to monitor our environment. The challenges involved in collecting environmental samples, duration, technicality and cost of measurement have led to various models for predicting unmeasured locations. This article presents geostatistical method using kriging techniques, which adopt the theory of regionalized variables, to characterize the spatial distribution of radionuclide in un-sampled locations using data obtained from sampled locations. Among other things, this paper presents results of application of this method to a study area. Spatial distribution of radionuclides reveal the non-uniform distribution in the study area. Though the radionuclides level in the study area are below global average set by United Nations Scientific Committee on the Effects of atomic Radiation (UNSCEAR), the spatial distribution map can be used to provide adequate information needed by regulatory authorities in identifying the contaminated area in need of remediation.
\end{abstract}

Keywords: Radionuclides, Kriging interpolation and Spatial mapping

\section{INTRODUCTION}

$\mathrm{R}$ adionuclides are unstable isotopes that emit ionizing radiations to attain stability. Emitted radiations have reportedly led to various health effects in exposed humans, ranging from cancer to skin burns, depending on exposure level [1]. They are one of the major concerns to human health, and they exist in various geological formation such as water, soil and rocks.

Potassium-40 and the decay series of uranium and thorium are the major naturally-occurring radionuclides in the environment [2]. They are widespread in the earth's environment and exist in environmental media such as rocks, soils, water, air and plants $[3,4]$. Other than the natural sources of radionuclides which account for about $85 \%$ of the annual ionizing radiation received by members of the public [5], anthropogenic activities such as nuclear accident, nuclear testing, mineral explorations, industrial activities and agrochemicals used in agricultural practices have been reported to enhance its level in the environment [4, 6-8].

The varying concentration of naturally-occurring radionuclides in the soil is due to the geographic and geological influence on its non-uniform distribution across the earth surface $[4,9]$. Several studies [7, 1012] have reported that regions with granitic rock have high concentrations of radionuclide in soil compared to regions with sedimentary rock. Mining and other anthropogenic activities have also enhanced its level above the recommended threshold in the environment [13].

Due to non-uniform distribution and presence of radionuclide above recommended threshold level in some regions coupled with associated health effects, monitoring and assessment of radionuclides' distribution is essential $[2,4,9,12]$. The rest of this article gives an overview of sources, effects and spatial distribution of radionuclides. This article also presents results of investigation and modelling of spatial distribution of naturally-occurring radionuclides in a selected study area.

\section{SOURCES OF RADIONUCLIDES}

Soil radioactivity is a result of naturally-occurring radionuclides present in the environment [14]. This is as a result of weathering of bedrock, the main reservoir of the primordial radionuclides, releases uranium (U), thorium (Th), and potassium $(\mathrm{K})$ to the soil and other geological formations. These can migrate to the environment via weathering of rocks and minerals, erosion and dust particles. Naturallyoccurring radionuclides are not uniformly distributed 
in soils and rocks, but vary from one region to another depending on the geological, geographic and anthropogenic activities of each region $[3,15]$.

Soil is a significant source of radiation exposure as well as a direct source of radionuclides leading to contamination of agricultural lands and products. They play essential role in the human food chain and are employed in human health risk assessments of ionizing radiation exposure in the environment [16, 17]. Soil radioactivity level is influenced by the radionuclide level in the bedrock and soil contamination has been widely associated with industrial and mining activities [12]. Monged, Hassan [6] ascribed enhanced level of radionuclides in soil to both natural and anthropogenic sources, highlighting the contribution from mining and industrial wastes along with agrochemicals to soil radioactivity level in the environment [18].

Radioactive materials from mining, agrochemicals, industrial and chemical waste, deposited in the environment can migrate to noncontaminated fields and water bodies via wind dispersal and erosion [19, 20]. Characterization of environmental contaminants in terms of concentration and distribution is essential in environmental monitoring and protection. Hence, the knowledge of the distribution of soil radionuclides is important in establishing baseline data for radiation impact assessment, radiation protection and exploration.

\section{EFFECT OF RADIONUCLIDES}

Humans are regularly exposed to ionizing radiation as a result of interaction with their environment either by inhalation of radioactive dust, ingestion of radioactive materials or direct exposure to a radioactive source $[1,4]$. Emitted radiation from naturally-occurring radionuclides has sufficient energy to cause ionization, resulting in either stochastic or non-stochastic effect of radiation. Stochastic and non-stochastic effects of radiation exposure depend primarily on the dose and duration of exposure. Stochastic effects such as cancer, teratogenic and genetic mutation are associated with long-term low-level radiation exposure. Nonstochastic effects are non-cancerous health effects such as burns and radiation sickness/radiation poisoning, and are associated with acute radiation exposure or short-term, high-level radiation exposure [1].

The dispersal of radioactive dust, radon gas, and its radioactive progeny from anthropogenic sources of radionuclides to the surrounding environment is a global concern because of the human health risk associated with it [14]. The principal radiation risk from exposure to naturally-occurring radionuclides in soil and other environmental media is the gamma radiation from radium decay leading to irradiation of body tissues [15].

Most populace are concerned about medical and occupational exposure risk of non-ionizing radiation, but often neglect risks due to exposure to ironizing radiation resulting from environmental radionuclide. Ironizing radiation are capable of causing genetic damage and cancer to the public, especially in children [16]. Radiological impact from exposure to naturally-occurring radionuclide is due to gamma rays exposure and irradiation of body tissues.

Due to the health risk associated with radiation and heavy metals' exposures, many government and international bodies such as International Commission on Radiation Protection (ICRP), World Health Organization (WHO) have adopted measures to minimize exposures. Such measures include setting threshold limits and implementing precautionary measures whenever the dose is found to be above recommended limits.

\section{Spatial Distribution}

Estimation of environmental variable in unsampled location, with the same anthropogenic loads of contamination is essential in environmental studies due to their non-uniform distribution, time, cost and technicality involve in measurement [17, 18]. Also, the need to determine areas requiring remediation as a result of increasing industrial and agricultural activities, at minimal cost is enough motivation to monitor and investigate the spatial distribution of these contaminants in our environment $[17,18]$.

Geo-statistical method is an important tool for mapping regional and local soil pollution and are often used to produce contamination maps. It is based on the theory of regionalized variable. They are used to reveal the spatial variability of environmental variables while providing quantitative basis for interpolating and predicting unmeasured location [19, 20]. 
Kriging techniques, based on the overall spatial arrangement of sampled location (auto-correlation) and the distance between the measured and prediction point, are widely used in environmental science to characterize spatial patterns and variability of pollutants concentration [9, 21, 22]. According to Dindaroğlu [9], Kriging technique is one of the accurate linear estimator and widely known techniques used in spatial predictions due to its reliability in estimating surface variables. Kriging technique is widely used in environmental science to characterize spatial patterns and variability of pollutants concentration $[9,21,22]$. It uses the property of semi-variance to express the degree of relationship between points on a surface by considering both the distance and the degree of variation between known data points when estimating values in unknown areas.

\section{Methodology}

In this study, Kriging technique was used for generating spatial mapping model for a selected study area in Rustenburg of South Africa. The study area comprises of cultivated as well as uncultivated farmlands. Basic theory underlying the Kriging technique is outline below as follows.

Kriging technique are defined as the optimal weighted average of the neighboring sampled data in an un-sampled location, is given as equation (1) [23].

$$
\hat{Z}\left(s_{o}\right)=\sum_{i=1}^{N} \lambda_{i} Z\left(s_{i}\right)
$$

where $Z(s)$ represents value at location s $(\mathrm{x}, \mathrm{y}), \varepsilon(s)$ is random errors with spatial dependence and $\mu$ is constant on which the model is based, $\lambda_{i}$ is an unknown weight for the measured value at the $i$-th location $[9,19,20]$.

The statistical prediction is minimized to make an unbiased prediction using $\left(Z\left(s_{0}\right)-\sum_{i=1}^{N} \lambda_{i} Z\left(s_{i}\right)\right)^{2}$ to obtain the kriging equation

$$
\Gamma * \lambda=g
$$

according to Johnston, Ver Hoef [21]. The matrix $\Gamma$, is created using semivariogram

$$
\gamma(h)=\frac{1}{2 N(h)} \sum_{N(h)}[Z(S)-Z(S+h)]^{2}
$$

for all possible measured location $u$, where $\mathrm{N}(\mathrm{h})$ is the number of pairs for lag distance $h$ and vector $\mathrm{g}$ is estimated using the location to be predicted by applying its Euclidean distance from all measured points. Ordinary kriging equation

$$
\lambda=\Gamma^{-1} * g \quad(4)
$$

is solved to predict the un-sampled location using equation (1).

In this study, Geostatistical analysis and geographic information system-based spatial mapping was used to study the spatial distribution of measured ${ }^{238} \mathrm{U}$, ${ }^{232} \mathrm{Th}$ and ${ }^{40} \mathrm{~K}$ in the farming area of Rustenburg. Activity concentration of naturally-occurring radionuclides was measured using a well calibrated broad energy hyper pure germanium detector. In the study area, measured activity concentration of naturally-occurring radionuclides is observed to be below the global average reported by United Nations Scientific Committee on the Effects of Atomic Radiation [4].

\section{RESUlTS AND DisCUSSION}

The spatial distribution of the three measured naturally-occurring radionuclides presented in Figure 1 to 3 , reveals the uniform distribution of naturally-occurring radionuclides in the study area. This observation is attributed to the geological and lithological homogeneity of the study area [24-26]. Figures 1, 2 and 3 show the activity concentration of naturally occurring radionuclides to vary from $(6.0$ to 31.0$) \mathrm{Bq} / \mathrm{kg}$, (5.0 to 24.0$) \mathrm{Bq} / \mathrm{kg}$ and $(15.0$ to 135.0) $\mathrm{Bq} / \mathrm{kg}$ for ${ }^{238} \mathrm{U},{ }^{232} \mathrm{Th}$ and ${ }^{40} \mathrm{~K}$. The slight variation observed in distribution of ${ }^{238} \mathrm{U},{ }^{232} \mathrm{Th}$ and ${ }^{40} \mathrm{~K}$, is due to different land use, which include farming, industries, mining, and residential [27]. Spatial distribution of radionuclides provides easy and comprehensive interpretation of the spread of radionuclides in the environment.

The average activity concentration of ${ }^{238} \mathrm{U},{ }^{232} \mathrm{Th}$ and ${ }^{40} \mathrm{~K}$ measured in the study area is found to be $17.03 \pm 0.98 \mathrm{~Bq} / \mathrm{kg}, 12.93 \pm 1.47 \mathrm{~Bq} / \mathrm{kg}$ and $82.56 \pm$ $7.80 \mathrm{~Bq} / \mathrm{kg}$ respectively. They are below the global average reported by United Nations Scientific Committee on the Effects of atomic Radiation (UNSCEAR). This indicate the area is radiological safe for living and agricultural purposes. Spatial distribution map can be employed in the identification of regions in need of remediation. As a result, it is essential in environmental monitoring and 


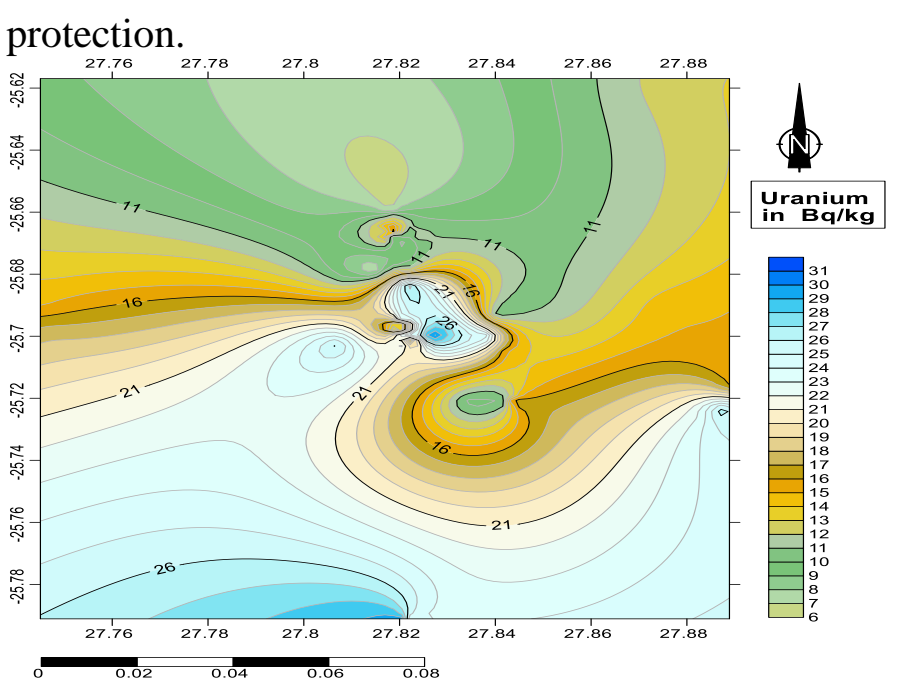

Figure 1: Spatial distribution of ${ }^{238} \mathrm{U}$ in the study area

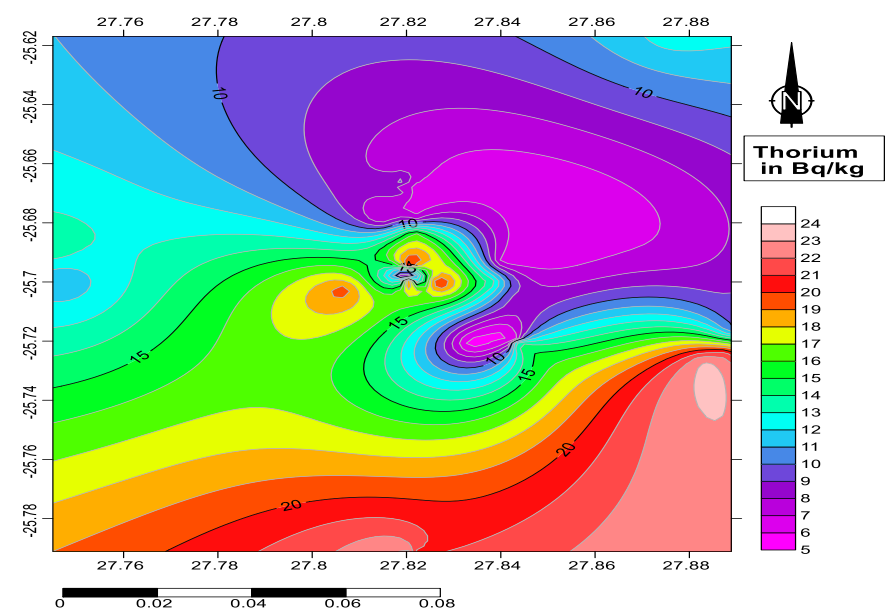

Figure 2: Spatial distribution of 232Th in the study area

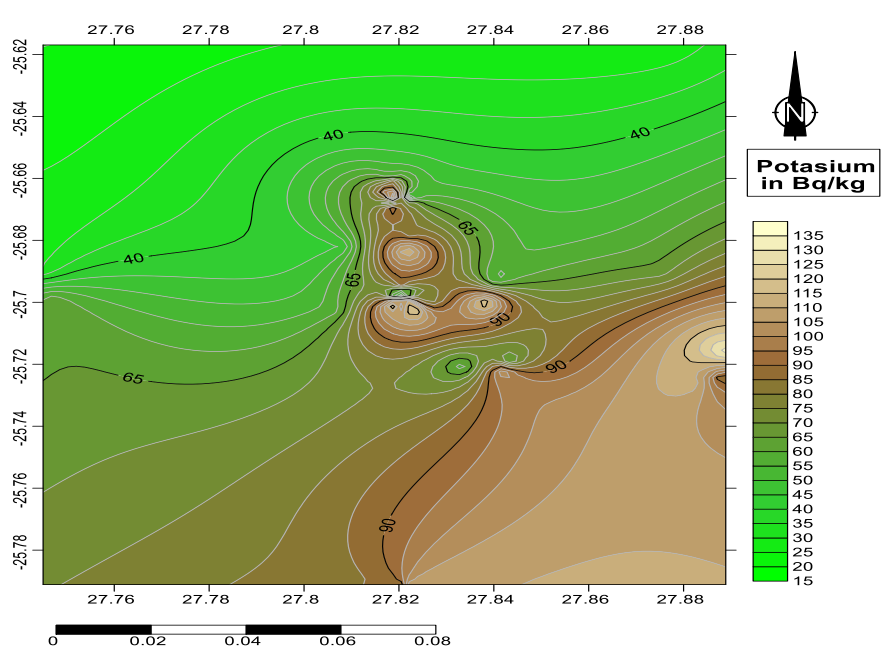

Figure 3: Spatial distribution of ${ }^{40} \mathrm{~K}$ in the study area

\section{CONCLUSIONS}

The potential health impact and regional variation of radionuclides in the earth as a result of geological and anthropogenic influence have resulted in continual investigation of its concentration and distribution in the environment for proper environmental monitoring and protection from its associated health risk globally.

The cost, effects, difficulty and technicality involved in collecting and measuring environmental data, coupled with its non-uniform distribution in the earth, have necessitated the need to develop environmental model for the study of spatial distribution of radionuclides to predict its concentration in unmeasured location using data obtained from measured location.

\section{REFERENCES}

1. Cember, H., T.E. Johnson, and P. Alaei, Introduction to Health Physics. MedPh, 2008. 35(12): p. 5959.

2. Obed, R., I. Farai, and N. Jibiri, Population Dose Distribution due to Soil Radioactivity Concentration Levels in 18 Cities Across Nigeria. Journal of Radiological Protection, 2005. 25(3): p. 305.

3. Ajayi, O.S., K.O. Balogun, and C.G. Dike, Spatial distributions and dose assessment of natural radionuclides in rocks and soils of some selected sites in southwestern Nigeria. Human and Ecological Risk Assessment: An International Journal, 2017. 23(6): p. 1373-1388.

4. UNSCEAR, Sources and Effects of Ionizing Radiation: Sources. Vol. 1. 2000: United Nations Publications.

5. WNA, Naturally-occurring Radioactive Materials (NORM). 2014, World Nuclear Association.

6. Monged, M.H., H.B. Hassan, and S.A. El-Sayed, Spatial Distribution and Ecological Risk Assessment of Natural Radionuclides and Trace Elements in Agricultural Soil of Northeastern Nile Valley, Egypt. Water, Air, \& Soil Pollution, 2020. 231(7): p. 1-24.

7. Navas, A., J. Soto, and J. Machín, Edaphic and Physiographic Factors Affecting the Distribution of Natural Gamma-emitting Radionuclides in the Soils of the Arnás Catchment in the Central Spanish Pyrenees. European Journal of Soil Science, 2002. 53(4): p. 629-638.

8. Otwoma, D., et al., Radioactivity and dose assessment of rock and soil samples from Homa Mountain, Homa Bay County, Kenya. 2012.

9. Dindaroğlu, T., The use of the GIS Kriging technique to determine the spatial changes of natural radionuclide concentrations in soil and forest cover. Journal of Environmental Health Science and Engineering, 2014. 12(1): p. 130.

10. Ramasamy, V., S. Senthil, and V. Meenakshisundaram, Distribution of Natural Radionuclides and Minerals in Beach Sediments from North East Coast of Tamilnadu, India. African 
Journal of Basic and Applied Sciences, 2009. 1(1-2): p. 15-20.

11. Ramola, R., et al., Radionuclide Analysis in the Soil of Kumaun Himalaya, India, using Gamma ray spectrometry. Current Science, 2011: p. 906-914.

12. Jibiri, N. and I. Okeyode, Activity concentrations of natural radionuclides in the sediments of Ogun River, Southwestern Nigeria. Radiation protection dosimetry, 2011. 147(4): p. 555-564.

13. Azeez, H.H., H.H. Mansour, and S.T. Ahmad, Effect of Using Chemical Fertilizers on Natural Radioactivity Levels in Agricultural Soil in the Iraqi Kurdistan Region. Polish Journal of Environmental Studies, 2019.

14. Lottermoser, B. and P. Ashley, Tailings dam seepage at the rehabilitated Mary Kathleen uranium mine, Australia. Journal of Geochemical Exploration, 2005. 85(3): p. 119-137.

15. Abdelouas, A., Uranium Mill Tailings: Geochemistry, Mineralogy, and Environmental Impact. Elements, 2006. 2(6): p. 335-341.

16. Kamiya, K., et al., Long-term effects of radiation exposure on health. The lancet, 2015. 386(9992): p. 469-478.

17. Linnik, V.G., et al., Spatial Distribution of Heavy Metals in Soils of the Flood Plain of the Seversky Donets River (Russia) based on Geostatistical Methods. Environmental Geochemistry and Health, 2020: p. 1-15.

18. Chu, H.-J., et al., Delineating the Hazard Zone of Multiple Soil Pollutants by Multivariate Indicator Kriging and Conditioned Latin Hypercube Sampling. Geoderma, 2010. 158(3-4): p. 242-251.

19. Matheron, G., Principles of geostatistics. Economic geology, 1963. 58(8): p. 1246-1266.

20. Dai, L., H. Wei, and L. Wang, Spatial distribution and risk assessment of radionuclides in soils around a coal-fired power plant: a case study from the city of Baoji, China. Environmental research, 2007. 104(2): p. 201-208.

21. Johnston, K., et al., The principles of geostatistical analysis. 2003. 4980.

22. White, J., R. Welch, and W. Norvell, Soil Zinc Map of the USA using Geostatistics and Geographic Information Systems. Soil Science Society of America Journal, 1997. 61(1): p. 185-194.

23. Lin, Y.-P., et al., Factorial and indicator kriging methods using a geographic information system to delineate spatial variation and pollution sources of soil heavy metals. Environmental Geology, 2002. 42(8): p. 900-909.

24. Olagbaju, P., et al., Background radiation level measurement using hand held dosimeter and gamma spectrometry in Ijebu-Ife, Ogun State Nigeria. International Journal of Radiation Research, 2021. 19(3): p. 591-598.

25. Ramasamy, V., S. Senthil, and V. Meenakshisundaram, Distribution of natural radionuclides and minerals in beach sediments from north east coast of Tamilnadu, India. Afr J Basic Appl Sci, 2009. 1(1-2): p. 15-20.

26. Viljoen, M. and R. Hieber. The Rustenburg Section of Rustenburg Platinum Mines Limited, with Reference to the Merensky Reef. in Mineral deposits of southern Africa. 1986.

27. Nde, S.C., et al., Modelling the dynamics of the cancer risk due to potentially toxic elements in agricultural soils, in the upper Crocodile River catchment, North-West province, South Africa. Ecotoxicology and Environmental Safety, 2021. 211: p. 111961 . 